\title{
Reaction kinetic analysis of damage rate effects on defect structural evolution in $\mathrm{Fe}-\mathrm{Cu}$
}

\section{$\operatorname{AUTHOR}(\mathrm{S})$ :}

Yoshiie, T.; Xu, Q.; Sato, K.

\section{CITATION:}

Yoshiie, T. ... [et al]. Reaction kinetic analysis of damage rate effects on defect structural evolution in Fe-Cu. Nuclear Instruments and Methods in Physics Research Section B: Beam Interactions with Materials and Atoms 2013, 303: 37-41

ISSUE DATE:

2013-05-15

URL:

http://hdl.handle.net/2433/179299

\section{RIGHT:}

(C) 2013 Elsevier B.V.; This is not the published version. Please cite only the published version.; この論文は出版社版でありません。引用の際に は出版社版をご確認ご利用ください。 
Reaction kinetic analysis of damage rate effects on defect structural evolution in $\mathrm{Fe}-\mathrm{Cu}$

\author{
T. Yoshiie, Q. Xu and K. Sato
}

Research Reactor Institute, Kyoto University

Asashiro, Kumatori-cho, Sennan-gun, Osaka-fu 590-0494, Japan

In $\mathrm{Fe}-\mathrm{Cu}$ alloys, $\mathrm{Cu}$ precipitates are formed during high-energy particle irradiation. If there exists energetic binding between vacancies and $\mathrm{Cu}$ atoms, vacancy clusters (voids) are formed in precipitates at an initial stage of irradiation, separate from voids in the matrix, because of the migration of $\mathrm{Cu}$ atoms with vacancies. In this paper, the damage rate dependence on the formation and annihilation of voids in the precipitates and in the matrix is simulated by reaction kinetic analysis. The initial formation of voids at precipitates, the annihilation of them with an increased dosage and new formation of voids in the matrix are simulated, and the results are compared with the experiments. In a high damage rate of 3.3.x10 $10^{-7} \mathrm{dpa} / \mathrm{s}$, the formation of voids in $\mathrm{Cu}$ precipitates is not significant, but the formation of voids in the matrix is dominant, different from those in a low damage rate of $1.5 \times 10^{-10} \mathrm{dpa} / \mathrm{s}$.

\title{
1. Introduction
}

For the development of nuclear materials, accelerated irradiation experiments are usually employed to reduce irradiation time. In order to estimate the lifetime of nuclear reactor pressure vessel steels from the irradiation experiment using materials testing reactors, we have to understand the damage rate dependence of defect structural evolution. Clustering of point defects and precipitation are strong damage rate dependence.

As a model system, $\mathrm{Fe}-0.6 \mathrm{wt} . \% \mathrm{Cu}$ alloy was chosen. $\mathrm{Cu}$ atoms are almost insoluble in Fe below $800 \mathrm{~K}$ and $\mathrm{Cu}$ precipitates are formed in $\mathrm{Fe}-\mathrm{Cu}$ alloys during thermal aging at high temperatures, as well as upon high-energy particle irradiation [1,2]. The precipitates obstruct dislocation motion and induce embrittlement in Fe-based alloys containing $\mathrm{Cu}$ impurities, such as old commercial reactor pressure vessel (RPV) steels. Besides $\mathrm{Cu}$ precipitates, defect clusters such as interstitial clusters and vacancy clusters are also formed during irradiation, which are further contributing factors to increasing hardness and decreasing ductility of RPV steels.

Nagai et al. have been reported the formation of voids and $\mathrm{Cu}$ precipitates, and concluded that voids were surrounded by $\mathrm{Cu}$ precipitates [3]. $\mathrm{Xu}$ et al. also detected the coexistence of $\mathrm{Cu}$ precipitates and voids [4, 5]. In our previous simulations of the $\mathrm{Fe}-\mathrm{Cu}$ system, 
we did not consider the energetic binding between $\mathrm{Cu}$ atoms and vacancies. Without the binding, the formation of voids in $\mathrm{Cu}$ clusters did not occur [6,7]. In this paper, reaction kinetic analysis, using rate equations, was performed to simulate the $\mathrm{Cu}$ precipitation in the $\mathrm{Fe}-\mathrm{Cu}$ system introducing the binding energy between $\mathrm{Cu}$ atoms and vacancies. The damage rate dependence of precipitation and void growth was also discussed.

\section{Reaction kinetic analysis}

The calculation model is based on the rate theory. The alloy calculated is Fe-0.6wt.\% $\mathrm{Cu}$. The model describes the reaction rates among various point defect reactions [8, 9]. The following assumptions were made in the calculation:

(1) Mobile defects are interstitials, vacancies and $\mathrm{Cu}$-vacancy pairs.

(2) The binding and the thermal dissociation are considered for $\mathrm{Cu}$-vacancy pairs.

(3) The time dependence of eleven variables is calculated up to $1 \mathrm{dpa}$ : the concentration of interstitials, interstitial clusters (interstitial type dislocation loops), vacancies, vacancy clusters (voids) in the matrix, $\mathrm{Cu}$ atoms, $\mathrm{Cu}$-vacancy pairs, $\mathrm{Cu}$-vacancy clusters, the total interstitials in interstitial clusters, the total vacancies in vacancy clusters in the matrix, the total vacancies in void in $\mathrm{Cu}$-vacancy clusters, and the total $\mathrm{Cu}$ atoms in $\mathrm{Cu}$-vacancy pairs. The cluster size is taken as an average one.

(4) Di-interstitials and di-vacancies are set for stable nuclei of clusters [10,11]. Direct formation of clusters in cascades, interstitial clusters (three interstitials) and vacancy clusters (three vacancies), is also taken in the simulation. The formation rate is assumed to be $1.0 \times 10^{-5}$ of the total point defect production as explained in 4.1.

(5) The material temperature is $573 \mathrm{~K}$ during irradiation.

The concentrations of interstitials $\left(\mathrm{C}_{I}\right)$, vacancies $\left(C_{V}\right), \mathrm{Cu}$ atoms in the matrix $\left(C_{C u}\right)$ and $\mathrm{Cu}$-vacancy pairs $\left(C_{V C u}\right)$ are expressed as: 


$$
\begin{aligned}
& \frac{d C_{I}}{d t}=P_{I}-2 Z_{I, I} M_{I} C_{I}^{2}-Z_{I, V}\left(M_{I}+M_{V}\right) C_{I} C_{V}-Z_{I, V C u}\left(M_{I}+M_{V C u}\right) C_{I} C_{V C u} \\
& -Z_{I, I C} M_{I} C_{I} S_{I C}-Z_{I, V C} M_{I} C_{I} S_{V C}-Z_{I, P C} M_{I} C_{I} S_{P C}-M_{I} C_{I} C_{S}-N_{I} P_{I C}, \\
& \frac{d C_{V}}{d t}=P_{V}+B_{V, C u} M_{V} C_{V C u}+B_{V, P C} M_{V} S_{P C}-2 Z_{V, V} M_{V} C_{V}^{2}-Z_{I, V}\left(M_{I}+M_{V}\right) C_{I} C_{V} \\
& -Z_{V, C u} M_{V} C_{V} C_{C u}-Z_{V, V C u}\left(M_{V}+M_{V C u}\right) C_{V} C_{V C u}-Z_{V, V C} M_{V} C_{V} S_{V C}-Z_{V, I C} M_{V} C_{V} S_{I C} \\
& -Z_{V, P C} M_{V} C_{V} S_{P C}-M_{V} C_{V} C_{S}-N_{V} P_{V C}, \\
& \frac{d C_{V C u}}{d t}=Z_{V, C u} M_{V} C_{V} C_{C u}-B_{V, C u} M_{V} C_{V C u}-Z_{I, V C u}\left(M_{I}+M_{V C u}\right) C_{I} C_{V C u} \\
& -Z_{V, V C u}\left(M_{V}+M_{V C u}\right) C_{V} C_{V C u}-Z_{V C u, C u} M_{V C u} C_{V C u} C_{C u}-2 Z_{V C u, V C u} M_{V C u} C_{V C u}^{2} \\
& -Z_{V C u, V C} M_{V C u} C_{V C u} S_{V C}-Z_{V C u, I C} M_{V C u} C_{V C u} S_{I C}-Z_{V C u, P C} M_{V C u} C_{V C u} S_{P C}-M_{V C u} C_{V C u} C_{S}, \\
& \frac{d C_{C u}}{d t}=Z_{I, V C u}\left(M_{I}+M_{V C u}\right) C_{I} C_{V C u}+B_{V, C u} M_{V} C_{V C u}-Z_{V, C u} M_{V} C_{V} C_{C u}-Z_{V C u, C u} M_{V C u} C_{V C u} C_{C u},
\end{aligned}
$$
where $P$ is the production rate of interstitials and vacancies, and $Z$ is the number of sites in the spontaneous reaction of each process. $M$ is the mobility of defects and is expressed as $v \exp \left(-\frac{E_{M}}{k T}\right)$, where $v$ is an effective frequency associated with vibration of the defects in the direction of the saddle point and taken as $10^{13} / \mathrm{s} . E, k$, and $T$ are the migration energy, the Boltzmann constant and temperature, respectively. $S$ is the sink efficiency to mobile defects $[10,11] . N$ is the number of atoms in clusters formed directly in cascades. $B$ is the dissociation probability of vacancies with voids and is expressed as $\exp \left(-\frac{K}{k T}\right)$, where $K$ is the binding energy. $K_{V, C u}, K_{V, P C}$ and $K_{V, V o i d}$ are the binding energies between vacancies and $\mathrm{Cu}$ atoms, between vacancies and voids in $\mathrm{Cu}$-vacancy clusters, and between vacancies and voids in the matrix, respectively. The subscripts $I, V, \mathrm{Cu}, V C u, P C, I C, V C$, and $S$ denote interstitials, vacancies, $\mathrm{Cu}$ atoms, $\mathrm{Cu}$-vacancy pairs, $\mathrm{Cu}$-vacancy clusters, interstitial type dislocation loops, voids, and surfaces, respectively. The surfaces are expressed by sink efficiency Cs. It is almost $(\mathrm{a} / \mathrm{L})^{2}$ at the center of foil specimens in the case of random walk of point defects, where $a$ and $h$ are atomic distance and foil thickness, respectively [10].

The concentrations are fractional units. $S$ is expressed as

$$
\begin{aligned}
& S_{V C}=\left(48 \pi^{2} R_{V C} C_{V C}^{2}\right)^{1 / 3}, \\
& S_{I C}=2\left(\pi R_{I C} C_{I C}\right)^{1 / 2}, \\
& S_{P C}=\left(48 \pi^{2}\left(R_{P V}+R_{P C u}\right) C_{P C}^{2}\right)^{1 / 3} .
\end{aligned}
$$

The nucleation rates of interstitial type dislocation loops (concentration, $C_{I C}$ ), voids in the matrix $\left(C_{V C}\right)$, and $\mathrm{Cu}$-vacancy clusters $\left(C_{P C}\right)$ are: 


$$
\begin{aligned}
& \frac{d C_{I C}}{d t}=P_{I C}+Z_{I, I} M_{I} C_{I}^{2}, \\
& \frac{d C_{V C}}{d t}=P_{V C}+Z_{V, V} M_{V} C_{V}^{2}, \\
& \frac{d C_{P C}}{d t}=Z_{V, V C u}\left(M_{V}+M_{V C u}\right) C_{V} C_{V C u}+Z_{V C u, V C u} C_{V C u}{ }^{2}+Z_{V C u, C u} M_{V C u} C_{V C u} C_{C u} .
\end{aligned}
$$

$P_{I C}$ and $P_{V C}$ are the production rates of interstitial type dislocation loops and voids directly from cascades, and determined to be $1.0 \times 10^{-5}$ of the total point defect production as explained in 4.1 .

The total accumulation of interstitials in loops $\left(R_{I}\right)$, that of vacancies in voids $\left(R_{V}\right)$ from the matrix and that of vacancies in voids from $\mathrm{Cu}$-vacancy clusters $\left(R_{P V}\right)$ are

$$
\begin{aligned}
& \frac{d R_{I C}}{d t}=2 Z_{I, I} M_{I} C_{I}^{2}+Z_{I, I C} M_{I} C_{I} S_{I C}+Z_{V C u, I C} M_{V C u} C_{V C u} S_{I C}-Z_{V, I C} M_{V} C_{V} S_{I C}+N_{I} P_{I C} \\
& \frac{d R_{V C}}{d t}=2 Z_{V, V} M_{V} C_{V}^{2}+Z_{I, V C} M_{V} C_{V} S_{V C}+Z_{V C u, V C} M_{V C u} C_{V C u} S_{V C}-Z_{I, V C} M_{I} C_{I} S_{V C}+N_{V} P_{V C}, \\
& \frac{d R_{P V}}{d t}=2 Z_{V, V C u}\left(M_{V}+M_{V C u}\right) C_{V} C_{V C u}+2 Z_{V C u, V C u} M_{V C u} C_{V C u}{ }^{2}+Z_{V C u, C u} M_{V C u} C_{V C u} C_{C u} \\
& -Z_{V C u, P C} M_{V C u} C_{V C u} S_{P C}-Z_{I, P C} M_{I} C_{I} S_{P C}+Z_{V, P C} M_{V} C_{V} S_{P C}-B_{V, P C} M_{V} S_{P C} .
\end{aligned}
$$

The total accumulation of $\mathrm{Cu}$ atoms in $\mathrm{Cu}$-vacancy clusters $\left(R_{P C u}\right)$ is

$$
\begin{aligned}
& \frac{d R_{P C u}}{d t}=Z_{V, V C u}\left(M_{V}+M_{V C u}\right) C_{V} C_{V C u}+2 Z_{V C u, V C u} M_{V C u} C_{V C u}^{2}+2 Z_{V C u, C u} M_{V C u} C_{V C u} C_{C u} \\
& -Z_{V C u, P C} M_{V C u} C_{V C u} S_{P C} .
\end{aligned}
$$

The parameters used are listed in Table 1 . The values marked by * were adjusted to fit to previous experimental results [5], and an experimental result shown in Fig. 6 as discussed in 4.1 .

\section{Results}

The change of the concentrations in the point defects, the point defect clusters, $\mathrm{Cu}$ atoms, $\mathrm{Cu}$-vacancy pairs, $\mathrm{Cu}$ atoms in $\mathrm{Cu}$ clusters, and vacancies in $\mathrm{Cu}$-vacancy clusters under a damage rate of $1.5 \times 10^{-8} \mathrm{dpa} / \mathrm{s}$ is shown in Fig. 1. The increase of $\mathrm{Cu}$ atoms in $\mathrm{Cu}$ clusters, the decrease of isolated $\mathrm{Cu}$ atoms in the matrix, and the growth of interstitial type dislocation loops and voids in the matrix are seen. Figure 2 shows the relationship between the concentration of vacancies and $\mathrm{Cu}$ atoms in $\mathrm{Cu}$-vacancy clusters as three damage rates. At the initial stage of irradiation, $\mathrm{Cu}$ atoms and vacancies increases linearly, and then the vacancy concentration decreases at the dose indicated in each figure. The decrease is the dissociation of vacancies from voids in $\mathrm{Cu}$-vacancy clusters. 
The dose dependence of the concentration of vacancies in voids in the matrix and in $\mathrm{Cu}$-vacancy clusters is compared in Fig. 3. We determined the binding energies of vacancies in voids in $\mathrm{Cu}$-vacancy clusters and voids in the matrix to be $1.0 \mathrm{eV}$ and $1.59 \mathrm{eV}$, respectively so as to fit experimental results as discussed in 4.1. Therefore the decrease of vacancies in $\mathrm{Cu}$-vacancy clusters is caused by the low binding energy between vacancies and voids in $\mathrm{Cu}$-vacancy clusters. The total vacancy concentrations in voids in $\mathrm{Cu}$-vacancy clusters and voids in the matrix at three irradiation damage rates are shown in Fig. 4 with dose. The vacancy concentration of high damage rate is higher than that of low damage rate in the range lower than $10^{-1} \mathrm{dpa}$. This damage rate dependence is the same as those with no binding energy between vacancies and $\mathrm{Cu}$ atoms [6,7]. The slop of the line before and after matrix voids formation is very similar. It can be explained as follows. The time dependence of vacancy accumulation in voids $\left(d R_{V C} d d t\right)$ and in vacancy-Cu clusters $\left(d R_{P V} / d t\right)$ is functions of many variables such as $C_{V}$ and $C_{I}$. These valuables are almost constants or smooth functions of time (dpa) as shown in Fig. 1. Therefore $d R_{V C} / d t$ and $d R_{P V} / d t$ are almost constants, and $R_{V C}$ and $R_{P V}$ increase linearly with time (dpa).

Figure 5 shows the relationship between the total vacancy concentration in voids in $\mathrm{Cu}$-vacancy clusters and in the matrix, and $\mathrm{Cu}$ concentration in $\mathrm{Cu}$-vacancy clusters. It can be seen that the relationship between $\mathrm{Cu}$ concentration and the total accumulated vacancy concentration is almost linear in the high damage rate of $3.3 \times 10^{-7} \mathrm{dpa} / \mathrm{s}$.

\section{Discussion}

\subsection{Comparison with experiments}

The authors have reported the formation of $\mathrm{Cu}$ precipitates and point defect clusters in $\mathrm{Fe}-\mathrm{Cu}$ binary model alloys [4,5]. Results of positron annihilation experiments indicated that $\mathrm{Cu}$ precipitates were formed in these irradiations with different damage rates. $\mathrm{Cu}$ precipitates did not grow monotonously when increasing the irradiation dose. Figure 6 shows examples of coincidence Doppler broadening measurements of $\mathrm{Fe}-0.6 \mathrm{wt} \% \mathrm{Cu}$ irradiated under improved temperature control with an irradiation facility SSS at the Kyoto University Reactor $\left(1.5 \times 10^{-8}\right.$ dpa/s [16], 1'-9') at $573 \mathrm{~K}$ and with Japan Materials Testing Reactor $\left(3.3 \times 10^{-7} \mathrm{dpa} / \mathrm{s}\right.$, a-d) of Japan Atomic Energy Agency at $563 \mathrm{~K}$. The irradiation doses in the figure are listed in Table 1. Two parameters, $S$ and $W$, are defined as the ratio of the low momentum $\left(\left|\mathrm{P}_{\mathrm{L}}\right|<4 \times 10^{-3} \mathrm{~m}_{0} \mathrm{c}\right)$ and high momentum $\left(20 \times 10^{-3} \mathrm{~m}_{0} \mathrm{c}<\left|\mathrm{P}_{\mathrm{L}}\right|<30 \times 10^{-3} \mathrm{~m}_{0} \mathrm{c}\right)$ regions in the Doppler broadening spectrum, respectively, to the total region [4,5]. $S$ represents the smaller Doppler shift resulting from annihilation of positrons with valence electrons, and the increase in the size or density of vacancies causes $S$ to increase. $W$ comes from annihilation of positrons with core electrons, and the increase in size or density of $\mathrm{Cu}$ precipitates increases $W$. The changes in $S$ and $W$ are not 
independent. The change in size and density of voids or precipitates can change both $S$ and $W$, since $S$ and $W$ are defined as the ratio of certain regions in the Doppler broadening spectrum to the total region. For example, in pure $\mathrm{Fe}$, there is no formation of $\mathrm{Cu}$ precipitates, but the formation of voids increases $S$ and consequently decreases $W$ as shown in Fig. 6 . The decrease of $S$ parameter from 7' $\left(3.0 \times 10^{-3} \mathrm{dpa}\right)$ in Fig. 6 means the decrease of vacancy concentration in $\mathrm{Cu}$-vacancy clusters. In our simulation as shown in Fig. 2 and Fig. 5, the start of the decrease at $3.0 \times 10^{-3} \mathrm{dpa}$ was replicated by adjusting values marked by $*$ in Table 1 . For example, if $B_{V, P C}$ decreased, the start of the decrease of vacancy accumulation $\left(3.0 \times 10^{-3} \mathrm{dpa}\right)$ became high dose, and if $P_{V C}$ increased, the vacancy accumulation in voids was higher than that in experiments.

\subsection{Damage rate dependence of $\mathrm{Cu}$ precipitation}

The $\mathrm{Cu}$ precipitation in $\mathrm{Cu}$-vacancy clusters has strong damage rate dependence. In the simulation of the high damage rate of $3.3 \times 10^{-7} \mathrm{dpa} / \mathrm{s}$, the precipitation continues to a high dose as shown in Fig. 2. It is caused by the consumption of vacancies by vacancy-interstitial mutual annihilation. The computational result (Fig. 5) shows that the total vacancy concentrations in voids in the matrix and in $\mathrm{Cu}$-vacancy clusters at $7.8 \times 10^{-2} \mathrm{dpa}$ and $2.6 \times 10^{-1} \mathrm{dpa}$ are $4.1 \times 10^{-4}$ and $2.5 \times 10^{-4}$, respectively. The $\mathrm{Cu}$ concentrations in $\mathrm{Cu}$-vacancy clusters at $7.8 \times 10^{-2} \mathrm{dpa}$ and $2.6 \times 10^{-1} \mathrm{dpa}$ are $0.06 \%$ and $0.19 \%$, respectively. According to the calculation, $\mathrm{d}(0.2 \mathrm{dpa})$ of Fe-0.6wt.\% Cu with $3.3 \times 10^{-7} \mathrm{dpa} / \mathrm{s}$ in Fig. 6 should be at the left side of c $\left(7.4 \times 10^{-2} \mathrm{dpa} / \mathrm{s}\right)$. Therefore the present simulation is not fully replicating the experimental result. Smaller difference of $S$ between c and d in $\mathrm{Fe}-0.6 \mathrm{wt} . \% \mathrm{Cu}$ than that between $\mathrm{c}$ and $\mathrm{d}$ in $\mathrm{Fe}$ is, however, the evidence of the decrease of $S$ between $7.8 \times 10^{-2}$ dpa and $2.6 \times 10^{-1}$ dpa. In the low damage rate of $1.5 \times 10^{-10} \mathrm{dpa} / \mathrm{s}$, the precipitation was accelerated.

\subsection{Damage rate dependence of vacancy accumulation}

The vacancy accumulation in $\mathrm{Cu}$ clusters is caused by the binding between $\mathrm{Cu}$ atoms and vacancies. $\mathrm{Cu}$ atoms are added to precipitates with the help of vacancies, and vacancies also accumulate at the precipitate forming voids. The binding energy has not been reported yet. Even the volume size factor of $\mathrm{Cu}$ in $\mathrm{Fe}$ is not determined yet as $17.53 \%$ [17], 15\% [18] and $0.4 \%$ [19]. In order to explain the experimental results of the voids in $\mathrm{Cu}$ clusters, however, the binding between $\mathrm{Cu}$ atoms and vacancies is inevitable.

There are two types of vacancy accumulation. One is the void formation in $\mathrm{Cu}$ clusters. The other is that in the matrix without $\mathrm{Cu}$ atoms. The shrinkage of initially formed voids in $\mathrm{Cu}$-vacancy clusters is caused by evaporation of vacancies from $\mathrm{Cu}$-vacancy clusters. The binding energy of $1.0 \mathrm{eV}$ is used to fit the experimental result of $1.5 \times 10^{-8} \mathrm{dpa} / \mathrm{s}$. After the shrinkage of voids in $\mathrm{Cu}$-vacancy clusters, the growth of voids in the matrix occurs. It is caused 
by the difference of the binding energy between vacancies in voids in $\mathrm{Cu}$-vacancy clusters and those in voids in the matrix. The binding energy of $1.5 \mathrm{eV}$ is used for vacancies in voids in the matrix. The binding energy of vacancies in large voids is the same as the formation energy of vacancies. The formation energies of vacancies in $\mathrm{Fe}$ and $\mathrm{Cu}$ are $1.59 \mathrm{eV}$ [14] and $1.28 \mathrm{eV}$ [15], respectively. In small $\mathrm{Cu}$-vacancy clusters in $\mathrm{Fe}, \mathrm{Cu}$ atoms are bec structure and the formation energy of vacancies must be lower than that in fcc structure. Therefore the binding energy of 1.0 $\mathrm{eV}$ used is a reasonable value.

\section{Concluding remarks}

The damage rate dependence of $\mathrm{Cu}$ precipitation and void growth was simulated for $\mathrm{Fe}-\mathrm{Cu}$ alloy by using reaction kinetic analysis. The results almost replicated our previous coincidence Doppler broadening measurements. The shrinkage of voids in $\mathrm{Cu}$-vacancy clusters was explained by the easy evaporation of vacancies from voids surrounding by $\mathrm{Cu}$ atoms. In the low damage rate of $1.5 \times 10^{-10} \mathrm{dpa} / \mathrm{s}$, the precipitation was accelerated, indicating the promotion of the $\mathrm{Cu}$ precipitation in nuclear power reactors. Our experiments were upon a model alloy of $\mathrm{Fe}-\mathrm{Cu}$ and the composition was largely different from that in pressure vessel steels. However, there is a strong possibility of the same precipitation behavior in the steels.

The simulation was a preliminary one. For the next step, the following points should be included in the rate equations. 1) Initial inhomogeneous distribution of $\mathrm{Cu}$ atoms, 2) coalescence of $\mathrm{Cu}$ precipitate, 3) thermal dissociation of small clusters such as di-vacancies, 4) migration mechanism of $\mathrm{Cu}$-vacancy pairs.

\section{References}

[1] J.T. Buswell, C.A. English, M.G. Hetherington, W.J. Phythian, G.D.W. Smith and G.M. Worrall, Effects of radiation on materials, in 14th International Symposium, ASTM STP, Vol. II, N.H. Packan, R.E. Stoller and A.S. Kumar, eds., American Society for Testing and Materials, Philadelphia, PA, 1990, p.127.

[2] P.J. Othen, M.L. Jenkins, G.D.W. Smith and W.J. Phythian, Phil. Mag. Lett. 64 (1991) 383.

[3] Y. Nagai, Z. Tang, M. Hassegawa, T. Kanai, and M. Saneyasu, Phys. Rev.B, 63 (2001) 134110.

[4] Q. Xu, T. Yoshiie, and K. Sato, Phys. Rev. B 73 (2006) 134115.

[5] Q. Xu and T. Yoshiie, Phil. Mag. 91 ( 2011) 3716.

[6] S.Yanagita, Q.Xu,T. Yoshiie, H.Ino, Mater. Trans. 43 (2002) 1663.

[7] S.Yanagita,T. Yoshiie and H.Ino, J. Japan Inst. Metal. 64 (2000) 115.

[8] T. Yoshiie, Q. Xu, K. Sato, K. Kikuchi, M. Kawai, J. Nucl. Mater., 377 (2008) 132.

[9] T. Yoshiie, T. Ito, H. Iwase, Y. Kaneko, M. Kawai, I. Kishida, S. Kunieda, K. Sato, S. 
Shimakawa, F. Shimizu, S. Hashimoto, N. Hashimoto, T. Fukahori, Y. Watanabe, Q. Xu, S.

Ishino, Nucl. Inst. Meth. Phys. Res B 269 (2011) 1740-1743.

[10] N. Yoshida and M. Kiritani, Phys. Soc. Japan, 35 (1973) 1418.

[11] M. Kiritani , H. Takata, Y. Maehara, Phys. Soc. Japan, 38 (1975) 1677.

[12] H. E. Schaefer, D. Butteweg and W. Dander, Proc. Int. Conf. on Fundamental Aspects of Radiation Damage in Metals, Gatlinburg, 1975, eds. M. T. Robinson and R. W. Young, Jr. (CONF-751006, Natl. Techn. Inf. Service, Springfield, VA, 22161) p. 463.

[13] S. Takaki, J. Fuss, H. Kugler, U. Dedek and H. Schultz, Rad. Eff. 79 (1983) 87.

[14] K. Furderer, K.P. Doring, M. Gladisch, N. Haas, D. Herlach, J. Major, H. J. Mundinger, J. Rosenkranz, W. Schafer, L. Schimmele, M. Schomlz, W. Schwarz and A. Seeger, Mater. Sci. Forum 15-18 (1987) 125.

[15] H. E. Schaefer, W. Stuck, F. Banhart and W. Bauer, Mater. Sci. Forum, 15-18 (1987) 117.

[16] T.Yoshiie, Y.Hayashi, S.Yanagita, Q.Xu, Y.Satoh, H.Tsujimoto, T.Kozuka, K.Kamae, K.Mishima, S.Shiroya, K.Kobayashi, M.Utsuro and Y.Fujita, Nucl. Inst. Meth. Pys. Res., A498 (2003) 522.

[17] H. W. King, J Mater. Sci. 1 (1966) 79.

[18]J. Z. Jiang, U. Gonser, C. Gente, R. Bormann, Appl. Phys. Lett., 63 (1993) 1056.

[19] O. Coren o-Alonso, J. Coren o-Alonso, Intermetallics 12 (2004) 117. 
Table 1 Values used in simulation. The values with * were determined to fit experimental results as discussed in 4.1. $Z$ denotes the number of reaction sites without $Z_{I, I C}, Z_{V, I C}$, and $Z_{V C u, I C}$.

\begin{tabular}{ccccccccccc}
\hline$Z^{*}$ & $Z_{I, I C} *$ & $Z_{V C u, I C}{ }^{*}$ & $Z_{V, I C}{ }^{*}$ & $P_{I C}{ }^{*}$ & $P_{V C}{ }^{*}$ & $E_{I}$ & $E_{V}$ & $B_{V C u}{ }^{*}$ & $B_{V, P C}{ }^{*}$ & $B_{V, \text { Void }}{ }^{*}$ \\
\hline 10 & 44 & 40 & 40 & $10^{-5} P$ & $10^{-5} P$ & $0.15 \mathrm{eV}[12]$ & $0.57 \mathrm{eV}[13]$ & $0.1 \mathrm{eV}$ & $1.0 \mathrm{eV}$ & $1.59 \mathrm{eV}[14]$ \\
\hline
\end{tabular}

\begin{tabular}{cc}
\hline$C_{S}$ & $M_{V C u}{ }^{*}$ \\
\hline $10^{-10}[10]$ & $0.01 M_{I}$ \\
\hline
\end{tabular}

Table 2 Irradiation doses in Fig. 7. From 1' to 9' and from a to d were irradiated at $573 \mathrm{~K}$ with $1.5 \times 10^{-8} \mathrm{dpa} / \mathrm{s}$ and at $563 \mathrm{~K}$ with $3.3 \times 10^{-7} \mathrm{dpa} / \mathrm{s}$, respectively.

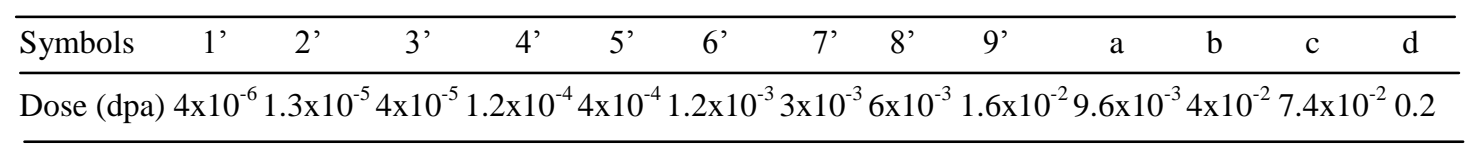

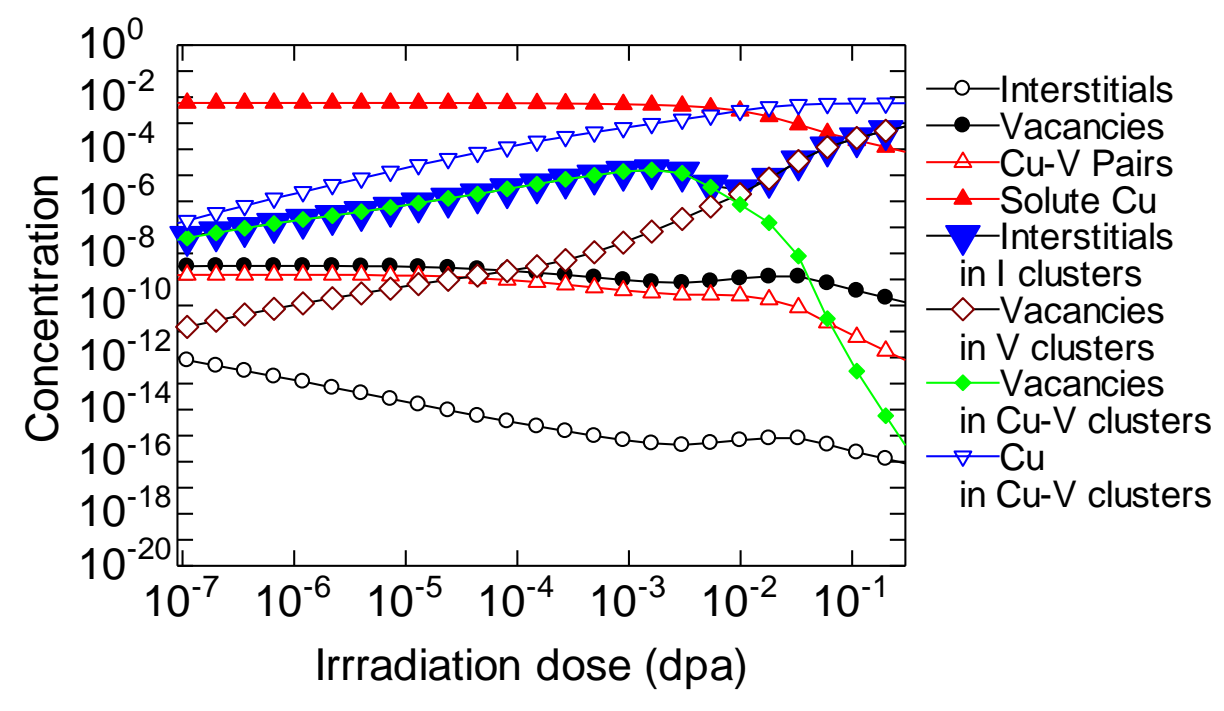

Fig. 1 The irradiation dose dependence of the concentrations of the point defects, the point defect clusters, $\mathrm{Cu}$ atoms, $\mathrm{Cu}$-vacancy pairs, $\mathrm{Cu}$ atoms in $\mathrm{Cu}$ clusters and vacancies in $\mathrm{Cu}$-vacancy clusters under a damage rate of $1.5 \times 10^{-8} \mathrm{dpa} / \mathrm{s}$. 




Total vacancy concentration in Cu- $\mathrm{V}$ clusters

Fig. 2 Damage rate dependence of vacancies and $\mathrm{Cu}$ concentrations in $\mathrm{Cu}$-vacancy clusters. The arrows indicate damages at points. $7.8 \times 10^{-2}, 9.9 \times 10^{-3}$ and $8.3 \times 10^{-4} \mathrm{dpa}$ are doses that half of $\mathrm{Cu}$ atoms are in $\mathrm{Cu}$-vacancy clusters. 


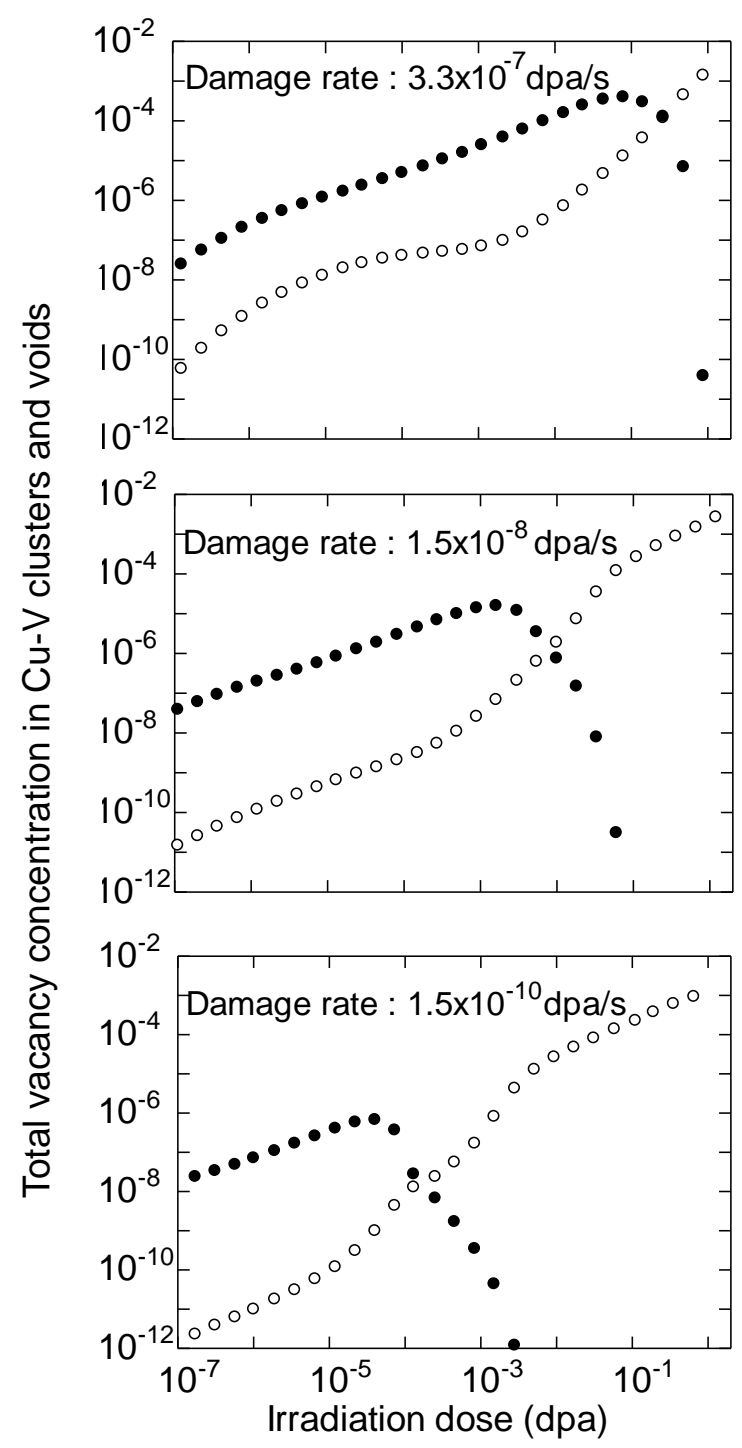

Fig. 3 Vacancy concentrations in voids in $\mathrm{Cu}^{-}$vacancy clusters (solid circles) and in the matrix (open circles) 


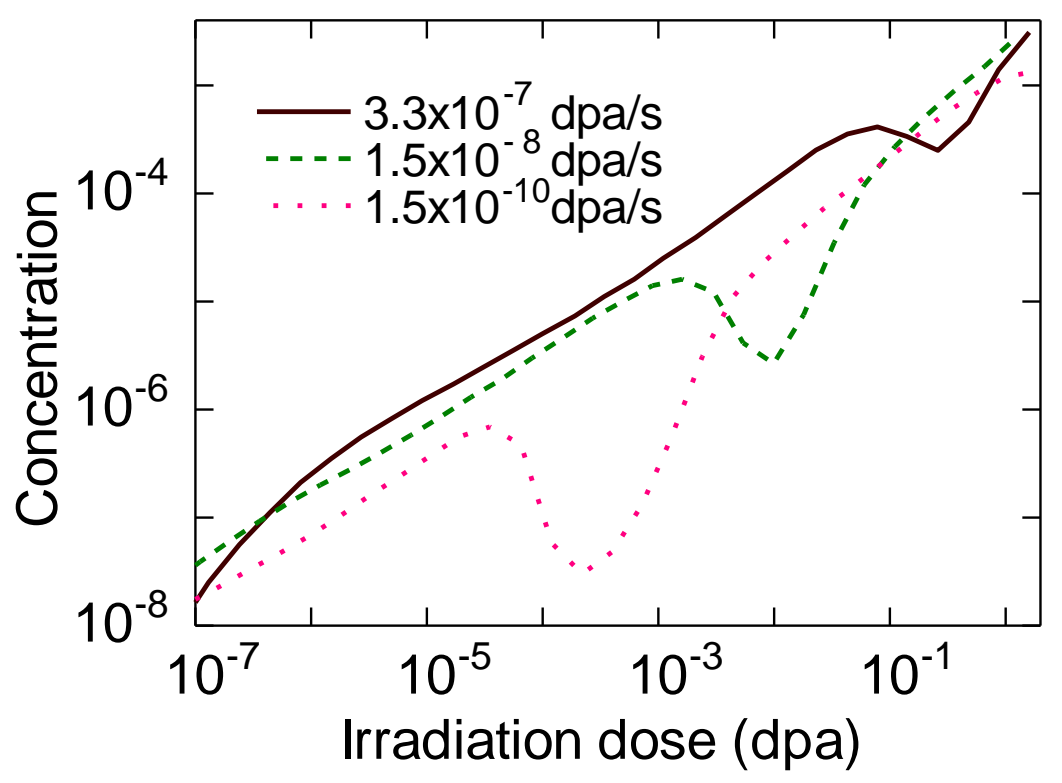

Fig. 4 Irradiation dose dependence of the total vacancy concentrations in voids in $\mathrm{Cu}-$ vacancy clusters and in the matrix.

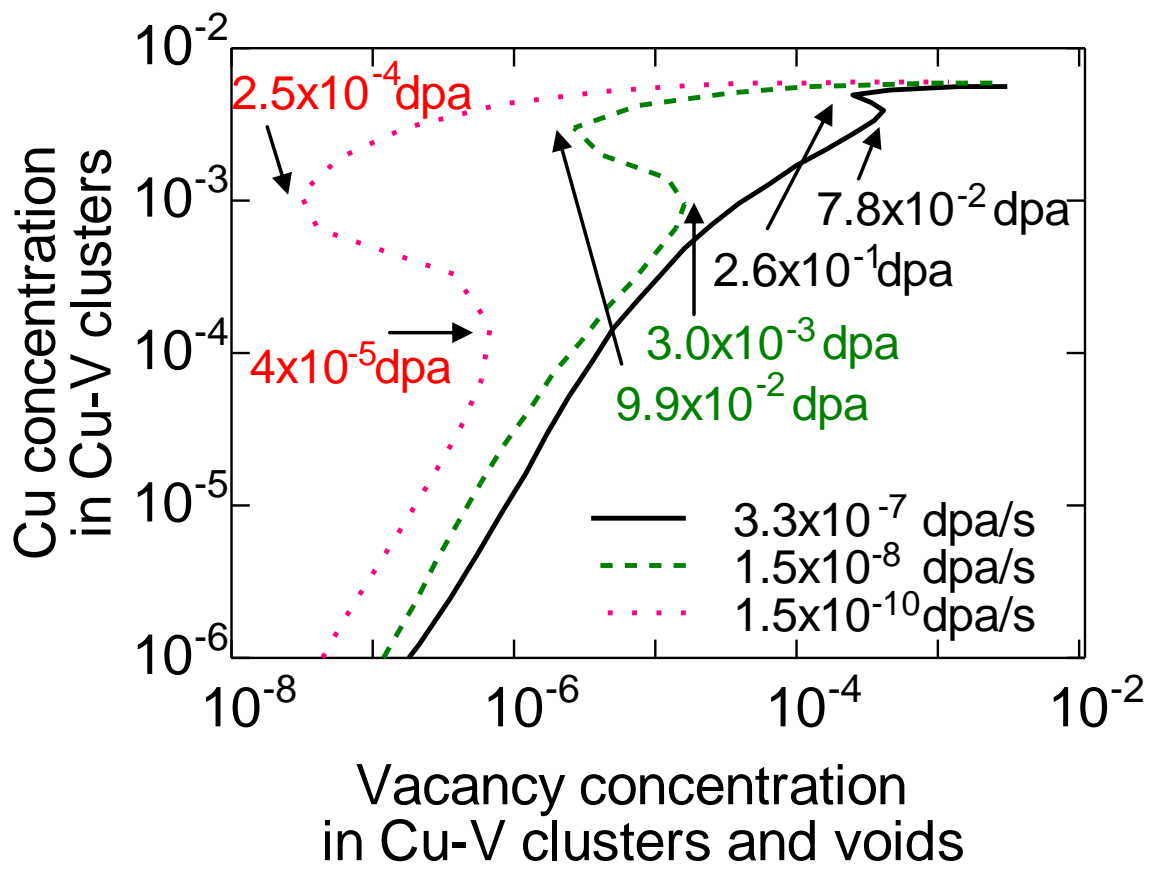

Fig. 5

Dose dependence of the concentration of $\mathrm{Cu}$ atoms in $\mathrm{Cu}^{-}$vacancy clusters, and vacancies in voids in $\mathrm{Cu}$-vacancy clusters and in the matrix. 


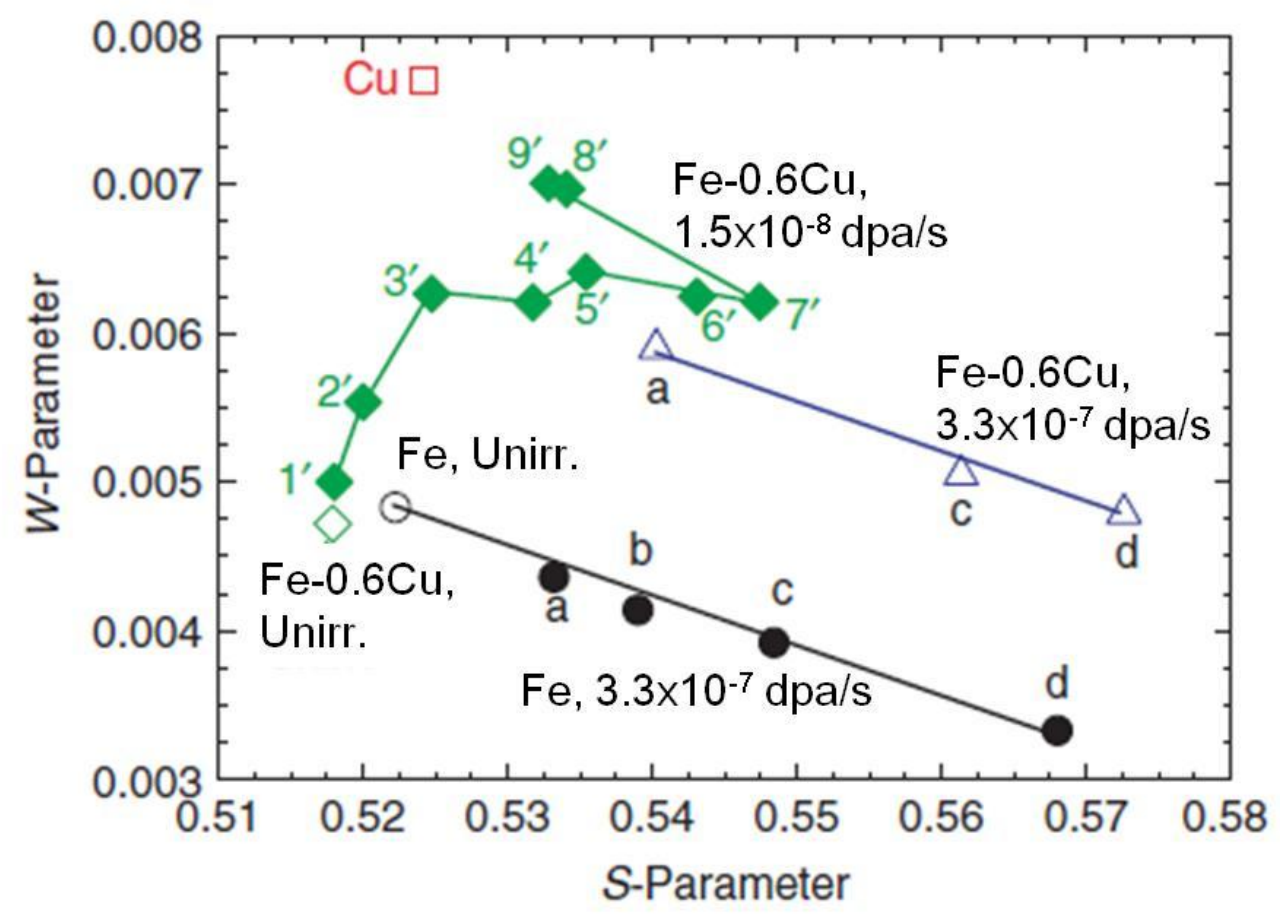

Fig.6 Coincidence Doppler broadening measurement of $\mathrm{Fe}-0.6 \mathrm{wt} . \% \mathrm{Cu}$ and $\mathrm{Fe}$ irradiated with $1.5 \times 10^{-8} \mathrm{dpa} / \mathrm{s}$ at $573 \mathrm{~K}$ and with $3.3 \times 10^{-7} \mathrm{dpa} / \mathrm{s}$ at $563 \mathrm{~K}$. Solid squares and open triangles are $\mathrm{Fe}-0.6 \mathrm{wt} . \% \mathrm{Cu}$, and solid circles are $\mathrm{Fe}$. Unirradiated $\mathrm{Cu}, \mathrm{Fe}$ and $\mathrm{Fe}-0.6 \mathrm{wt} . \% \mathrm{Cu}$ are also indicated in the figure. Irradiation doses are in Table 2. 